\title{
Facts and Theories in Protein Chemistry*
}

$\mathrm{I}^{\mathrm{N}}$ the last decade, many investigations of an exact nature have been made on the proteins in solution and in the solid phase. Unfortunately, by a dissipation of the available research energy among a wide variety of proteins and by a signal absence of co-operation among the researchers themselves, less significant advances have been made in the elucidation of fundamental principles than would otherwise have been the case. It was a happy inspiration, therefore, which brought together most of the authorities on protein chemistry in Europe at the Royal Society on November 17 to compare their experiences and discuss each other's difficulties.

Prof. The Svedberg (Uppsala) opened the conference with a vigorous and notably wide survey of recent developments in the physical chemistry of the proteins. According to precise physical measurements, protein particles have such characteristic and reproducible properties that it is no longer possible to deny them the right of classification as giant molecules. Sedimentation studies on native soluble proteins reveal a striking homogeneity in the sizes of individual molecules, and the method of electrophoresis reveals a similar homogeneity in their free charges. Measurements of protein molecular weights by sedimentation equilibrium or by a combination of sedimentation velocity and diffusion give values which, rather unexpectediy, conform to a law of simple multiples.

Assuming 17,600 as the unit of molecular weight, the values of some sixty native proteins so far investigated, including the giant hæmocyanin molecules with weights of several millions, may be expressed as multiples of this unit by factors containing powers of 2 and 3 . The rule is approximate only, suggesting the existence of some underlying architectural principle in the arrangement of the amino-acid residues. Differences in the percentage amino-acid composition of proteins may explain the spread of molecular weights above and below the simple multiple value. Determinations of osmotic pressure give values which agree well with molecular weights obtained by sedimentation methods. X-ray investigations of pepsin, insulin, lactoglobulin and hæmoglobin in the crystalline state have given values of 40,000 , $37,200,36,500$ and 69,000 respectively, while the ultracentrifuge gives $37,000,38,000,39,000$ and 68,000 .

* Substance of a discussion on "The Protein Molecule" held by the Royal Society on November 17 .
Viscosity measurements on anisotropic proteins may be correlated with the axial ratios of the corresponding molecular ellipsoids of rotation by means of equations proposed independently by Kuhn, Burgers and Polson. From the axial ratio the molecular frictional coefficient may be calculated, and this in turn supplies the necessary information for calculating molecular weights from diffusion data. Molecular weights thus obtained from viscosity and diffusion data agree with the ultracentrifuge values only when Polson's equation, which has a purely empirical basis, is used. Studies on the peptic digestion of egg albumin by Tiselius show that the decomposition products have a much lower electrophoretic mobility than the uncharged protein. This supports the view that the constituent units of a protein particle are bound together by specific chemical linkages and that the particle is in fact a single molecule.

Recent theories of protein structure proposed by Wrinch and by Bergmann and Niemann imply the chemical individuality of the protein molecule. These theories are important as a stimulus to further research ; but caution must be observed in their acceptance. In the case of Bergmann and Niemann's theory, which assumes a fundamental regularity in the arrangement of the amino-acid residues in the molecule, certain difficulties exist. For example, the theory gives a molecular weight of 69,000 for hæmoglobin based on a cysteine content of 0.5 per cent and assuming three cysteine residues per molecule. Ultracentrifugal and X-ray methods show, however, that hæmoglobin may be split reversibly into halves of approximately equal size.

Dr. Linderstrøm-Lang (Copenhagen) emphasized the value of enzymic degradation as a method of studying the structure of the protein molecule, especially in recent years with the advent of crystalline and relatively pure enzymes. Considerable care is still required in the interpretation of the results of these studies, since it is now becoming clear that some fundamental change scarcely distinguishable from denaturation is a necessary preliminary to the enzymic disruption of polypeptide bonds in the protein molecule. Dr. D. Wrinch (Oxford) gave a clear presentation with the aid of models of her 'cyclol' hypothesis, which assumes that the protein molecule is constituted of diazine and triazine rings arranged alternately in a kind of fabric which may be folded according to purely geometrical considerations. The spaceenclosing fabric with 288 amino-acid residues takes 
the form of a truncated tetrahedron and this represents the globular protein molecule of weight 35,000. Dr. A. Neuberger (London) pointed out that the presence of diazine and triazine rings in proteins is not supported by chemical facts. It has never been shown that a lactam-lactim tautomerism exists in peptides, nor has a polymerization of peptides to cyanidine-like rings been realized. The chemical and enzymic behaviour of proteins is also not in accordance with the cyclol hypothesis. The Bergmann and Niemann hypothesis was also criticized by Dr. Neuberger on the grounds that the limits of error in the present methods of estimating amino-acids are so great as to render the deductions made from them statistically of doubtful value.

Dr. G.S.Adair (Cambridge) showed that for hæmoglobin, egg albumin and serum albumin, the maximum values for the molecular radii calculated from measurements of diffusion made at Uppsala, were not more than 5 per cent greater than the minimum values calculated from measurements of the hydration and density of protein crystals suspended in sodium phosphate buffers. He also discussed the effects which salts have on the iso-electric points of proteins. Dr. K. O. Pederson (Uppsala) described new work on the dissociation of proteins, particularly the type of molecular splitting which one component of a binary mixture induces in the other. The dissociation is more marked when a carbohydrate-rich protein is mixed with a carbohydrate-poor one. It is also marked in serum in which there is evidence that phosphatides take a role similar to the carbohydrate. The X-fraction seen in the sedimentation diagram of normal serum is identical with the intermediate or $\beta$. globulin seen in electrophoresis, and this fraction according to Tiselius and Blix is the main carrier of the serum phosphatides. Changes which affect the serum calcium, for example, dialysis, addition of salts, etc., affect the sedimentation rate of the $\mathrm{X}$-component. The effect is probably on the phosphatide linkage.

Dr. Pederson suggested that these and other dissociation effects are best explained by postu. lating that the larger protein molecules consist of small primary protein units linked into a secondary structure by means of carbohydrate, phosphatide, nucleic acid, etc. This view received striking support from Mr. J. St. L. Philpot (Oxford), who described how the sedimentation constant of casein can be altered at will to any value between 6 and. 10.4 by the addition of calcium. This appears to be a case of primary protein units linked by a polyvalent inorganic ion. A surprising fact, however, is that only one boundary-an apparently homogeneous one-is present. It is possible that the primary protein units are very small, but if in fact they are about 100,000 in weight $\left(S_{w, 20^{\circ}}=6\right)$ the absence of two boundaries might be explained by postulating an extremely mobile form of calciumcasein equilibrium.

Prof. H. H. Weber (Münster) opened the afternoon session with a paper on the proteins of muscle, dealing particularly with myosin. Solutions of this protein show a high and anomalous viscosity and marked anisotropy of flow. Solutions more concentrated than 2 per cent cannot be obtained in the disorientated state, but orientated threads may be spun like artificial silk to much higher concentrations. These threads resemble muscle fibres closely in swelling power, tensile strength, elastic properties and X-ray appearances. Measurements of the double refraction and the eigendoppelbrechung of the stretched myosin thread show that these correspond quantitatively with the values for the $Q$-disks of muscle. The $Q$-disk consists therefore of fully orientated myosin rods. Complete elastic stretching of the myosin filament results from stretching of the rods themselves, the process consisting evidently in a straightening of folded filamentous molecules. Myosin may be denatured by heating above $40^{\circ} \mathrm{C}$, , the threads undergoing an irreversible decrease in double refraction and a marked contraction. The view is put forward that muscle contraction consists in a chemically induced denaturation of myosin molecules which is reversible in the circumstances pertaining to muscle. Dr. G. Boehm (Basle) showed a number of X-ray diagrams of stretched myosin threads. Prof. K. H. Meyer (Geneva) developed some interesting ideas on mechanically induced molecular transformations, citing the solubility and elastic changes caused in the crude material from the silk gland by simple stretching, and the crystallization of metastable selenium by similar treatment. $\mathrm{He}$ is of the opinion that blood plasma may be regarded as a supersaturated fibrinogen solution and that mechanical denaturation may suffice to explain the phenomena of blood clotting. Dr. W. T. Astbury (Leeds) referred to the elegant method of progressive piling of protein monolayers on a metal slide until it is possible to measure the thickness of a monolayer by means of a screw micrometer.

Dr. Evert Gorter (Leyden) discussed the behaviour of those proteins which spread easily on water surfaces and others, for example, fibrinogen and myosin, which only do so after treatment with traces of proteolytic enzymes. Spreading experiments only give information about one side of the film-fortunately the more important polar side in contact with the water. The view that spread proteins are denatured is not in agreement with all the facts. Denatured egg albumin does not spread, and pepsin and trypsin remain active as 
proteolytic enzymes after spreading. Spreading does not necessarily cause denaturation because the polar groups remain active and free. Denatura. tion by shaking, on the other hand, results from juxtaposition of polar surfaces in the foam so that only non-polar groups are exposed and the foam becomes insoluble. It is unlikely also that spread proteins are denatured since these are employed widely in the architecture of living tissues. Dr. J. F. Danielli (London) pointed out that, from a consideration of surface forces, it appears that the attraction between hydrocarbon residues of the amino-acids are sufficient to maintain a folded globular form in the native protein. These forces are insufficient, however, to maintain a specific rigid structure, and additional chemical bonds must be postulated for this purpose.

Miss D. Crowfoot (Oxford) followed by Prof. J. D. Bernal (London) discussed the technical difficulties in protein crystallography, especially those arising from the weakness of the reflections and from hydration of the crystals. Both speakers referred to the inadequacy of the X-ray data available on the proteins and to the necessity for caution in the interpretation of the results. Of the seven proteins so far examined, dried insulin is the simplest, having a rhombohedral cell containing only one Svedberg unit of 35,000 . One cannot be certain even in the case of insulin whether the crystallographic unit is a true unit or itself consists of sub-units. Prof. J. R. Marrack (London) discussed experiments with conjugated antibodies which lead to the conclusion that the antibodyantigen reaction is not due to simple combination of polar groups, but probably involves specific aminoacid configurations. Dr. E. R. Holiday (London) supported this view on the basis of immunity phenomena exhibited by serum albumin after incomplete digestion with pepsin.

\section{A. S. MCFarLane.}

\section{Sir Charles Parsons and Marine Propulsion}

$\mathrm{O}^{\mathrm{N}}$ $\mathrm{N}$ December 2, at the Institution of Mechanical Engineers, before an audience which included many engineers who have been closely associated with the application of the Parsons steam turbine to ships, Mr. S. S. Cook delivered the third Parsons Memorial Lecture, taking as his subject "Sir Charles Parsons and Marine Propulsion". Born in 1875, and like Parsons a Cambridge wrangler, Mr. Cook has been connected for a long period with the Parsons Marine Steam Turbine Company and is well known in engineering circles for his original investigations and his memoirs on the marine steam turbine.

The story which $\mathrm{Mr}$. Cook unfolded may perhaps be regarded by some as a thrice-told tale, for Sir Charles Parsons, either himself or in collaboration with others, placed on record in papers to technical institutions the various steps in the progress of the turbine as applied to steamships, but there are features in the story which when told by others only heighten our respect and admiration for Parsons when he was faced with difficulties which would have overwhelmed men of less determination. None of those who were present at the Diamond Jubilee Review of 1897 and saw the little Turbinia steam at more than 30 knots up and down the lines could have known that three years previously the same craft with her original machinery, to the intense disappointment of Parsons and his colleagues, had failed to obtain a speed of even 20 knots. "The spectators", said Mr. Cook, "may have been thrilled to see a tiny vessel racing down the lines at such unusual speed, but their feelings could have been nothing com. pared with those of the few on board the vessel, who had emerged so triumphantly from depressing failure into glorious success".

The Parsons turbine, it will be remembered, was invented in 1884 . For the next ten years or so it was used exclusively for driving electric generators, and it was not until the compound condensing turbine had shown its superiority over the best reciprocating engine that any steps were taken to apply it to ships. The speed at which it revolved seemed to some to rule it out for this purpose. In January 1894, however, after some preliminary work, Parsons took out Patent 394 for "Propelling a steam vessel by means of a steam turbine, which turbine actuates the propeller or paddle shaft directly or through gearing", and the pioneer company, the Marine Steam Turbine Company, was formed. The directors of the company were the Earl of Rosse, Parsons, N. G. Clayton, C. J. Leyland, J. B. Simpson and A. A. Campbell Swinton. After some experiments with models, the Turbinia was built. She was $100 \mathrm{ft}$. long and 44 tons displacement. Into her Parsons fitted a single water-tube boiler and a single radial flow turbine. Designed to develop 1650 h.p., the speed of the turbine was $1600-1700$ 